\title{
Resuscitation and resurrection: The ethics of cloning cheetahs, mammoths, and Neanderthals
}

\author{
Sariah Cottrell, Jamie $L$ Jensen and Steven $L$ Peck ${ }^{*}$
}

*Correspondence:
steven_peck@byu.edu
Brigham Young University,
155 WIDB, Provo, UT, USA

\begin{abstract}
Recent events and advances address the possibility of cloning endangered and extinct species. The ethics of these types of cloning have special considerations, uniquely different from the types of cloning commonly practiced. Cloning of cheetahs (and other endangered or vulnerable species) may be ethically appropriate, given certain constraints. However, the ethics of cloning extinct species varies; for example, cloning mammoths and Neanderthals is more ethically problematic than conservation cloning, and requires more attention. Cloning Neanderthals in particular is likely unethical and such a project should not be undertaken. It is important to discuss and plan for the constraints necessary to mitigate the harms of conservation and extinct cloning, and it is imperative that scientific and public discourse enlighten and guide actions in the sphere of cloning.

Keywords: Extinct; Endangered; Conservation; Ethics; Utilitarianism; Somatic cell nuclear transfer
\end{abstract}

\section{Main text}

Since the birth of Dolly the sheep in 1996 (Wilmut et al. 1997), 'cloning' animals generally means cloning via somatic cell nuclear transfer (SCNT). SCNT follows specific steps for cloning: an egg cell is prepared by having its nucleus removed; an adult (or somatic) cell has its nucleus removed; this nucleus is inserted into the prepared egg, which is then stimulated with an electrical shock inducing egg cell division. This embryo is implanted into the uterus of a surrogate mother, which if it takes, is later successfully born. The surrogate mother acts as a natural mother would during pregnancy, once the embryo implants into her uterus. The resulting individual, or clone, has nuclear DNA identical to the donor of the somatic cell. Over the decades, cloning has made stunning progress (See Figure 1), with cloned dogs and cats commercially available and livestock regularly cloned (Panarace 2007). Cloning is very expensive: the cost just to preserve tissue from a dog or a cat for future cloning is about \$1,000 USD per year (Shiels 2004), while the cost of having a dog or cat cloned ranges from $\$ 32,000$ to over $\$ 100,000$, averaging at around $\$ 50,000$ (Boyce 2006; News 2004; Flock 2012). Cloning livestock is less expensive, with a cloned cow costing at least $\$ 15,000$ and a pig costing $\$ 4,000$ (Plume 2009).

Cloning is not equally ethically appropriate for all species, so the question of whether we should try to clone for conservation or resurrection becomes complicated when applied to individual species. There are numerous concerns about cloning and how to

(c) 2014 Cottrell et al.; licensee Springer. This is an open access article distributed under the terms of the Creative Commons Attribution License (http://creativecommons.org/licenses/by/2.0), which permits unrestricted use, distribution, and reproduction in any medium, provided the original work is properly cited. 


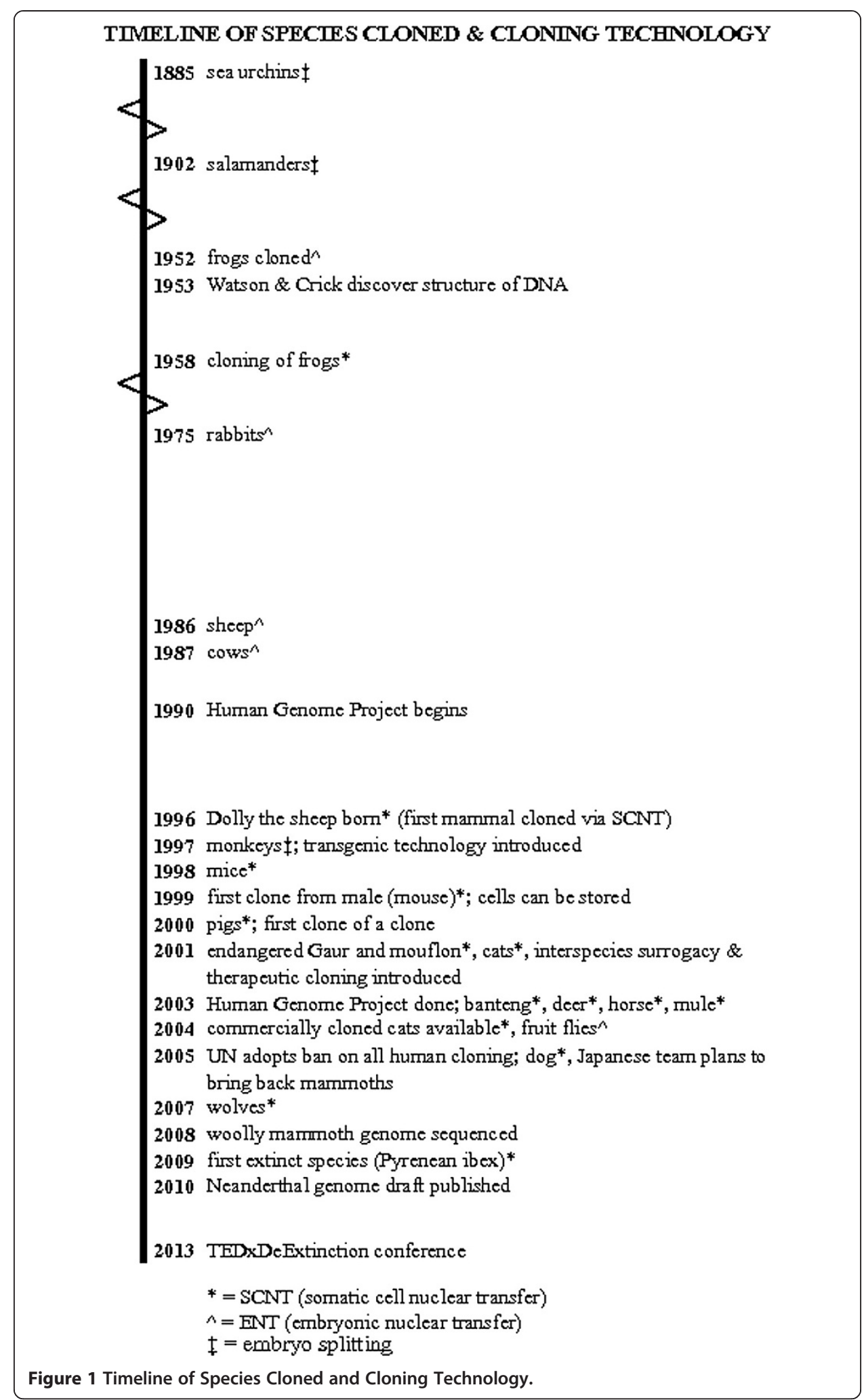

apply it. All of these applications of cloning were unthinkable before Dolly, but have since become common realities. Cloning has generated much ethical discussion in applications for animals and humans alike, with implications ranging from concerns 
about a violation of animal welfare (Fiester 2005) to human safety (Lane 2006) and the ramifications of 'playing God' (Chadwick 1982). After cloning Dolly, her creators wrote:

We were not thinking about...creating hillock upon hillock of identical sheep to guarantee a good night's sleep. We were not thinking about helping lesbians to reproduce without the help of a sperm bank of multiplying movie stars. We were certainly not thinking of duplicating dictators. (Wilmut and Highfield 2006)

Those who cloned Dolly foresaw neither the future they enabled, nor its ethical implications, and it is important to continue to examine these ethics. Before embarking on any cloning exercise, there are a number of ethical issues that ought to be considered: Why clone this species or individual and not others? What is the cost, and who should pay it? What will happen to the clone and its potential progeny? Under what circumstances is this a technology humans should use? There are many positive and negative effects cloning could have on individuals, populations, and ecosystems. There are many reasons that would seem to compel us to use cloning technology, yet this must be done, if at all, with careful attention to ethical consideration, including motivations behind cloning. Since Dolly, humans have moved from the position of cloning being impossible to a world of possibilities with new perspectives and motivations. For example, cloning pets can provide emotional mollification for some owners, and livestock clones can ensure financial and agricultural success to others; however, there are some cloning endeavors on the horizon that will have far-reaching consequences. Here we explore the implications of one of these: can we use cloning to save endangered species or resurrect extinct ones?

Cloning for conservation purposes may be the next step of cloning technology (Ryder and Benirschke 1997), and restoring extinct species may soon follow. Recent events (TEDx 2013; RT 2013; Gross 2013) and publications (Zimmer 2013a) have drawn attention to the realistic possibilities of cloning extinct species. These types of cloning have the potential to have a greater effect than changing the lives of pet owners or the livestock industry; it could change the course of natural history on our planet. In the face of today's ecological crises, could we use cloning to reduce or reverse the impact we've had on our world? Such questions need careful attention.

There are special concerns when cloning is applied to endangered and extinct species. There are a number of ways ethical theory can be used to explore this type of cloning. Here we will consider only two, deontological and utilitarian ethics, which represent two main branches of ethical theory. Other ethical viewpoints could be considered, such as animal rights arguments, narrative ethics, or evolutionary ethics that would bring to light other valid and legitimate concerns and approaches. While these views are important, we will restrict ourselves to the two aforementioned main views in this paper. Using deontological and utilitarian perspectives, we will examine the special considerations and ethics of cloning for conservation and cloning extinct organisms.

First, we will discuss the cheetah, an endearing and threatened species, as a specific case of conservation cloning. Second, to examine cloning extinct species, we will consider the cloning of woolly mammoths, commonly discussed and charismatic animals in conversations about extinct cloning. Finally, we will consider cloning Neanderthals. This closely related species has only recently become a candidate for cloning, although it has received relatively little discussion in bioethical literature. 


\section{Cloning for conservation: cheetah (Acinonyx jubatus)}

Much discussion has centered on the use of cloning as a tool to alleviate the current massive rate of mammalian extinction (Ehrenfeld 2006; Pina-Aguilar et al. 2009; Ryder and Benirschke 1997; Lee 2001; Ryder 2002). The concept of cloning endangered species is not new, but it is less common than cloning livestock or domestic animals. This type of cloning has the potential to have long-lasting and far-reaching effects if applied to endangered species, and could change much about conservation. Cheetahs are an especially interesting species to consider because they are a popular and threatened mammal with an unusual evolutionary bottleneck that has severely restricted their genetic diversity. This provides a basis for our thoughts on conservation cloning.

\section{Special considerations}

Conservation cloning has two special considerations: assessing which species to clone and how to address potential animal rights. Cloning via SCNT at this time is largely restricted to mammals. We are limited in our current cloning capabilities, and the long wait may be longer for whatever additional threatened species man wants to clone, particularly if that species is a bird or reptile. One species may be more imminently threatened than another, but it doesn't necessarily mean they will get priority:

Cloning is expensive-only charismatic animals are likely to be cloned....True, cheaper, easier, and more efficient cloning techniques are being developed, but the cloning of endangered rays, caecilians, or vipers may have to wait until we have done the showier rare birds and mammals. (Ehrenfeld 2006)

This is troubling for conservation efforts that would focus on species and ecosystems of all types. However, this reflects reality; charismatic animals are likely to receive first attention and larger funding than less popular species. Cloning a species for the first time is more expensive than an established cloning technique for an animal, and so the cost to clone a cheetah could easily reach $\$ 100,000$ USD and probably much more. Subsequent clones will become cheaper, but the price will remain high for some time. To the extent that these costs remain high, cloning a new animal will be expensive, and the reality discussed above is one in which the charm of the animal and not the threat of the species will dictate which species are addressed and when. Cheetahs, being a large member of the cat family, represent a species with a great deal of appeal and thus make an interesting case study.

\section{Positive ethical aspects of cloning cheetahs}

In justifying a decision to clone cheetahs, a Kantian (or deontological) view finds purchase for the cloning of endangered animals, be they charming or otherwise, through our sense of duty to values of stewardship and care for our planet and its inhabitants., This includes duties that demand we treat animals with kindness, which allows us to express moral responsibility towards animals and reflects and develops humane feelings towards our own and other species. Kantian ethics may also imply indirect duties toward animals such as ameliorating humanity's impact on the environment. Cloning cheetahs could be used as a way to fulfill this duty to the natural world. 
However, a utilitarian perspective may provide additional or alternative warrant. Cloning cheetahs could achieve societal and environmental benefits for many species. Societal benefits such as increased endangered species awareness and international cooperation are valuable, and the benefits of research necessary to clone this species are especially advantageous. Research gained in cloning a cheetah would assist in furthering cloning technology and, if it incorporates artificial genetic manipulation in an attempt to expand genetic variation in cheetah populations, it would advance gene therapy technologies, benefitting humans and other species. Cloning cheetahs could contribute to the overall eventual human wellbeing in addition to accruing conservation benefits.

The environmental effects of cloning cheetahs are also advantageous. Cloning may increase habitat conservation, as both donors and the public would be interested in providing adequate habitat for cloned animals. Increased habitat conservation will, in turn, serve a greater good by benefitting naturally-born cheetahs and other species within their habitats. The role of predators is important to ecosystem dynamics, and preserving cheetahs keeps the ecosystem balanced (Lima 1998) and whole-habitat benefits could be realized.

Cloning cheetahs not only benefits their habitats, but also affects the cheetahs themselves by expanding knowledge of their genetics and husbandry. The restricted gene pool of cheetahs is the result of a bottleneck event about 12,000 BP (Culver et al. 2010). Cheetah ranges and numbers have dwindled significantly in the last century (Durant et al. 2010). It is possible that humans, through genetic therapy and manipulation, may provide additional genetic variation in cheetah populations. The future of cheetah populations may depend on their genetic variability enabling them to better survive current selective pressures (Durant et al. 2010), and the long-term benefits of improved genetics in this already genetically restricted species may lead to healthier cheetah populations (Ryder and Benirschke 1997). Cloning cheetahs in conjunction with genetic manipulation would benefit both cheetahs and future species for which this technology might be employed. Cloning cheetahs could provide a great deal of good for a great number of species, including our own.

\section{Negative ethical aspects of cloning cheetahs}

Cloning cheetahs does not address the problems leading to their extinction (e.g. habitat loss, hunting) (Jabr 2013), so we cannot, in any practical sense, make it a universal maxim to clone all endangered or vulnerable species. Society is unlikely to provide resources to universalize this, and it may be irresponsible to create such a maxim. Of course, this does not forbid the cloning of cheetahs; it simply denies this as an ethical obligation.

Utilitarian drawbacks of cloning cheetahs include laws, costs, and resource allocation. Cloning is expensive, and exploring genetic manipulations for cloned cheetahs is costly. Another significant expensive may be the cost to individual cheetahs themselves. Cheetahs are protected ([CITES] 2012), and while cheetahs would be ideal donors (Ehrenfeld 2006), it may be counter-productive to use cheetahs as donors or surrogates for the clones. It has often taken hundreds of embryos and attempted pregnancies to produce viable clones (Jabr 2013), so this requires many eggs from donors and great risk to surrogate mothers. The death or serious injury of a surrogate is an unacceptable 
biological cost; the cost of many individuals to achieve even one viable clone outweighs the benefits of that clone. The use of an interspecies surrogate transfers this cost to another organism but does not eliminate this cost (Poland and Bishop 2002). Finally, clones introduced into the wild may constitute a biological cost on wild coalitions (a group of cheetahs), or possibly on the clone itself in the wild. Paying these costs can only be justified if the benefits outweigh those costs.

Another consideration would be the potential reallocation of resources. It is possible that cloning cheetahs would siphon funds that would otherwise have helped habitat preservation. The Cheetah Conservation Fund operates on an annual budget of around \$1.8 million (personal communication with B. Fellenstein, Cheetah Conservation Fund, May 2013). To lose money from this budget would seriously affect the organization's contributions to preservation. Assisted reproduction and other efforts are more effective for conservation than cloning (Pina-Aguilar et al. 2009; Ryder and Benirschke 1997), and the money spent in assisted reproduction is more likely to result in increased cheetah populations than cloning. This misplaced investment in cloning is frustrating to conservationists; however, there is no reason to assume that money donated to cloning cheetahs would otherwise have gone to conservation (Lee 2001). Since cloning does not necessarily remove money from other funds, it is only unethical in this sense if it detracts from conservation efforts.

\section{Conclusion on cloning cheetahs}

Cloning cheetahs is only unethical if its costs outweigh the benefits. Cloning a cheetah has considerable potential benefits to the preservation of a large number of species. If prudent conservationists realized even some of these benefits, then cloning a cheetah is an ethically admirable practice. In order for the cloning of cheetahs to retain its ethical value, however, it must avoid the potential costs described and it must not eliminate, replace, or reverse the overall goals of conservation.

\section{Extinct cloning: woolly mammoth (Mammuthus primigenius)}

'If you want to bring a species back to life, the mammoth would be almost as dramatic as a dinosaur' (Nicholls 2008). Cloning extinct species would be a dramatic event as it brings back into existence something thought to be permanently lost. It presents different ethical considerations than cloning domestic or endangered species. Consider the cloning of a wooly mammoth.

Mammoth remains have been found in the frozen North (Mueller 2009), theoretically preserving DNA and thus making cloning mammoths a possibility. Despite the alternative of creating mammoth-elephant hybrids (Lister and Bahn 2007; Stone 1999, 2002), this section focuses specifically on the ethics of cloning mammoths (see Figure 2, Information drawn from Lister, Adrian, and Paul Bahn. 2007. Mammoths: Giants of the Ice Age. Berkeley, CA: Univeristy of California Press: 22-23). After examining a problem unique to cloning any extinct species, we will explore the ethical factors of cloning mammoths.

\section{Special considerations}

One ethical concern about cloning mammoths stems from general anti-cloning arguments, amplified when applied to extinct species. It starts with the argument that cloning is 'playing God' and is intrinsically therefore wrong. It is unclear what is meant by 'playing God' and why exactly that is inherently wrong (for further reading on the 


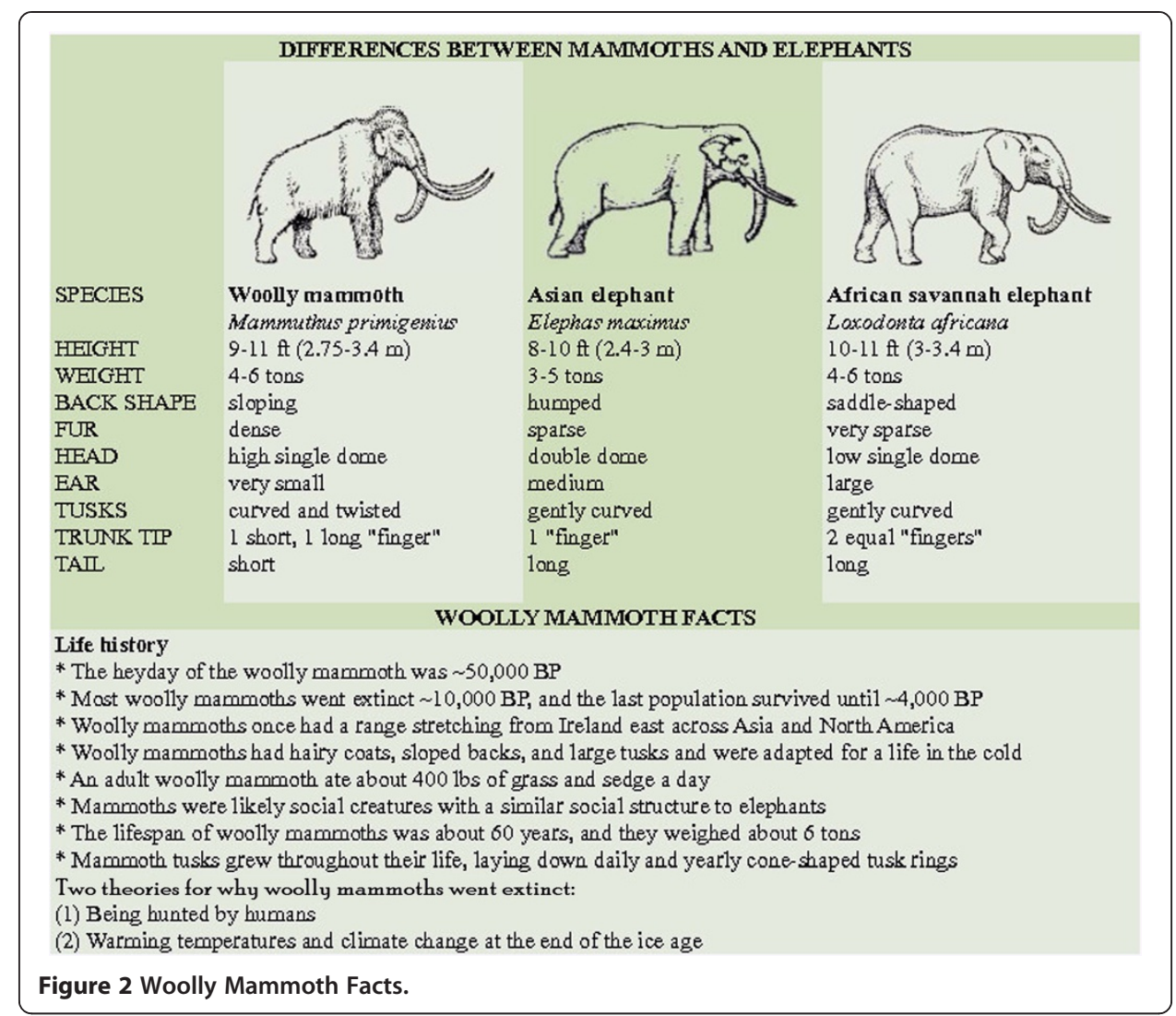

'playing God' argument, see (Van Den Belt 2009) and (Chadwick 1982)). Closely related to the 'playing God' argument is the 'unnatural' argument, which follows a similar pattern: that which is unnatural, is wrong; and natural is considered a nonnegotiable intrinsic value. Ruth Chadwick argued:

What is claimed when anything is objected to on the ground that it is 'unnatural' is far from clear, and it is no clearer in the case of cloning than anything else. It is not that cloning does not occur 'in nature'...the point is rather that cloning is unnatural for the species. (Chadwick 1982)

Despite the tenuousness of these arguments, they nonetheless carry intuitive appeal. Any opposition to cloning on the grounds that this sort of reproduction is 'unnatural' for the species is multiplied in the cloning of mammoths. Mammoths are extinct and do not currently exist on the earth; it is unnatural for them to be reproducing at all, much less via cloning. This is true regardless of what led to their extinction. Any living aspect of a mammoth is unnatural. However, the unnatural and playing God arguments have not prevented the cloning of extant animals, and it is unlikely that these alone would provide moral force that would forbid the cloning of mammoths.

\section{Positive ethical aspects of cloning mammoths}

Several perspectives support the ethical appropriateness of cloning mammoths. First there is a deontological consideration based on the possibility that humans contributed 
to mammoth extinction (Nogués-bravo et al. 2008; Thomas 2012). Ethicist Hank Greely (2013) recently asked, 'If we killed them and now we have the ability to bring them back, do we have a duty to bring them back? Do we owe it to them?' Is restoring a species that humans eliminated from the earth part of our mandate to 'keep' the earth as it was? If true, as de-extinction advocate Mike Archer suggests (Woodford 2000), there may be deontological reasons that support cloning mammoths if humans drove them to extinction. This duty, however, seems vague and unjustified. Humans already failed the mandate to preserve the species; does restoring them eliminate that failure? The implication would rest on the assumption that current humans are accountable for the actions of a few humans in the distant past. If humans hunted mammoths to extinction, it was likely a hunting-to-eat rather than a hunting-for-sport scenario, where killing mammoths kept our species alive, and it can be argued that we had a higher duty to our own species than another. Assigning human culpability to the status of a duty to humans not involved is problematic, so it cannot obligate us to clone mammoths. Furthermore, it is not certain that humans alone are responsible for the extinction of mammoths.

Cloning mammoths seems best considered under a utilitarian umbrella: the potential scientific progress and other benefits from cloning mammoths are numerous. Cloning mammoths would allow us to assess (to some extent) their life history and biology (Loi et al. 2011), possibly illuminating proboscidean evolution (Proboscidea is the order containing elephants and several extinct families including mammoths and mastodons), and could improve biotechnology in ways that will be applicable to multiple species, including humans. The monetary benefits alone are hefty: profits for researchers and laboratories; the worth of the mammoths and their offspring; money for zoos or institutions housing or working with mammoths; and most importantly, the possibility of considerable private funding. A resurrection project like this has great allure, and with private donations would not require or detract from government supported funds. The potential benefits of cloning a mammoth make it a very attractive project.

A final utilitarian consideration is Bentham's (1891) idea of providing the greatest happiness for the greatest number broadly construed. There is certainly a great deal of happiness available through cloning mammoths. For example, if the clones were kept in zoos rather than in the wild, it would minimize problems stemming from damaged ecosystems or species, and so maximize public enjoyment of the public viewing the mammoth. Cloned mammoths also provide fulfillment for creators, satisfaction for project donors, and enjoyment for those benefiting from any resulting tourism. Some of this will be true if the clones are reintroduced into the wild, but there are significant advantages in keeping the mammoth in a zoo, where the happiness of the clone itself is equal to or greater than other zoo animals-donors and researchers did not spend time and money only to let the clone languish in an ill-funded or inhumane zoo. Happiness from cloning mammoths, as a utilitarian measure of greater good, is abundant.

\section{Negative ethical aspects of cloning mammoths}

Many ethical arguments against cloning mammoths are rooted in either the same utilitarian or deontological views that promote it. Deontology based considerations are problematic because of the difficulty in universalizing this type of project. First for most 
extinct species it cannot be done because, (a) we do not have the ability (given the 521 year half-life of DNA, it is impossible to resurrect species that have been dead for more than a few million years [see (Allentoft 2012)]), nor can we reasonably know of all species that are extinct, or even all those that humans have driven to extinction, and (b) using resources to universally restore extinct species conflicts with other duties to our own species. Arguably, our highest duty is first to humans, and then to animals. Kant, for example, supports humane behavior towards animals as a reflection of our humanity (Kant c. 1790), but cloning mammoths themselves is not particularly reflective of our duties towards humanity, as this involves animals that are not currently in existence, perhaps dispensing with any obligations owed them. Furthermore, if the clones are destined for zoos or laboratories, then this is using them as a means and thus problematic. There is therefore no obligation for us to clone mammoths because it is too vaguely defined; however, it is not deontologically unethical to clone mammoths; it is simply not endorsed.

In light of this failure to satisfy deontological requirements, let us consider the utilitarian implications of cloning mammoths and the accompanying harms: societal harm, biological costs, and harm to the environment. First, let us consider the societal harms. Mammoths require laboratory support to bring them into existence. Cloning a mammoth will be very expensive, much more than cloning cheetahs. Similar to the cheetah scenario, it would be unethical to displace funds destined for other conservation causes to clone mammoths. Cloning mammoths may lead to other societal costs as well. Consider, for instance, the potential court battles (ownership, animal rights, money spent and earned in the project, etc.).

Further consider the societal and monetary costs of creating and enforcing mammoth conservation laws. Once a mammoth is cloned, it will be the only one of its kind to become an endangered species immediately at birth, and legally will qualify for those protections allocated to other endangered species. We would be creating an endangered species from one that is not currently endangered (nor currently living), and we would need to protect and preserve it. Just as the cloned cheetahs in the wild may merit greater protection than their naturally-born counterparts, cloned mammoths in the wild may receive more protection than other extant species indigenous to the cloned mammoth's environment. This is partly due to the fact that a small population or even just one mammoth is in more danger of extinction than are endangered elephants, and their endangered status is more severe because there will be fewer of them living than there are elephants. It is unacceptable for the moral status of a species that does not currently exist to exceed the moral status of animals that do exist. Legislation will have to be enacted to cover this case, and the legal ramifications could be immense. It is more important to conserve extant and endangered species than it is to clone extinct ones (Pina-Aguilar et al. 2009). If knowing that we can clone extinct species reduces society's incentive to preserve living and endangered species, then that makes it ethically problematic.

The cost of cloning mammoths affects surrogates, donors, and the clones themselves. The ideal surrogate and egg donor for mammoths is the Asian (also called Indian) elephant (Nicholls 2008), which is an endangered species. The endangered status of Asian elephants makes it 'completely unethical to use these animals for cloning a mammoth' (Pina-Aguilar et al. 2009). The cost on the elephants is too great; the individual elephants could develop ovarian tumors or be otherwise harmed through 
harvesting eggs or through the surrogate process, where mammoth fetuses may be unsuited to the uterus of the elephant (Nicholls 2008) and may do her harm. The potential death or harm to the elephants is too great a cost. This is problematic because Asian elephants are used as beasts of burden (History 2009), which is tolerated. If cloning is allowed, why not use elephants as mammoth surrogates? If humans desire to conserve elephants, perhaps these current practices ought to be reconsidered. (Aside: one difference between the two scenarios is the benefit to human livelihood from elephants as beasts of burden, which may outweigh the cost; but human life is not benefited through using elephants as surrogates for clones).

There are many other costs to the cloned mammoths themselves. Mammoths are believed to have been social creatures (Lister and Bahn 2007), and living in isolation would reduce the quality of a mammoth's life, necessitating multiple costly mammoth clones, at least until breeding colonies could be established, preferably of different genomes to allow for reproductive success and to minimize inbreeding. Furthermore, suppose the clones will be unable to survive our current climate and climate change, as is possible since climate was a factor in mammoth extinction (Thomas 2012; Nogués-bravo et al. 2008)? Add to this the potential difficulties seen in many clones (ex: congenital defects, abnormal development, reduced immunity, or vulnerability to aging or disease; see (Poland and Bishop 2002; Wells 2005; Cibelli et al. 2002)) which may be greater for extinct species with less-intact DNA. These biological and economic costs suggest cloning mammoths may not be ethical until these issues are addressed and technology has developed sufficiently to minimize them. In the utilitarian goal to minimize pain and maximize happiness, much must be done to mitigate the costs of cloning mammoths.

The potential environmental harms of cloning mammoths are uncertain but have serious and long-term implications. If mammoths are reintroduced into the wild, the habitat needs to withstand this. If the habitat intended to hold reintroduced wild mammoths would not support them, then it is not ethical to waste resources in cloning mammoths only to have them go extinct. Moreover, what of the habitat's ability to survive the mammoths? The habitat in which mammoths once lived does not exist. Reintroducing mammoths to the wild will not reestablish their former ecosystem (Rees 2001); the clones will have to forge a new one. Asian elephants already have a rocky relationship with humans due to depleted habitat, and they regularly kill humans and raid crops (Jadhav and Barua 2012). Might not cloned mammoths have similarly negative effects? Woolly mammoths were massive creatures that ate about $181 \mathrm{~kg}$ (400 lbs) of grass and sedge a day (Lister and Bahn 2007). Can the ecosystem that will house wild mammoths spare $181 \mathrm{~kg}$ of grass per mammoth per day? Mammoths may also take a large toll on ecosystems through competition or changing ecosystem dynamics, and could cause the extinction or threat of other species in the areas in which they are introduced. If a cloned mammoth would cause the extinction of another species, then cloning mammoths would be unethical and counter-productive for species conservation. The extant species must have moral priority.

\section{Conclusion on cloning mammoths}

Many effects of cloning mammoths are merely hypothetical, so where does our moral responsibility lie? On one hand, the potential harms and their long-term effects seem 
more certain and serious than the more vaguely-defined potential benefits. It is not very practical or utilitarian, especially if the clones are reintroduced into the wild and harm other species. On the other hand, many of the harms can be avoided if there are restrictions placed on mammoth cloning (namely, placing the clones in a zoo and requiring the project to be privately funded) to minimize negative impacts and maximize benefits. With these restrictions, the costs and benefits start to be manageable. In such circumstances, elements that make cloning mammoths unethical are equalized by the factors that make it ethical.

Even with these restrictions, cloning a mammoth is problematic. Conflicting deontological viewpoints also point to the conclusion that it is neither ethically obligatory nor ethically prohibited. The ethical stalemate allows researchers to proceed with cloning mammoths, provided they keep the clones in zoos and are privately funded. Researchers should consider these ethical issues, and there is some worry that they will fail to do so:

Enthusiasts seem unperturbed by the ethical problems associated with mammoth resurrection and oddly uninterested in finding a sound justification for the process.

For [some], raising the mammoth is simply an engineering goal, with no

fundamental obstacles in the way except the will to forge ahead. (Levy 2011)

It is important that the ethical problems of cloning mammoths not be ignored and, if attempted, that the practice adhere to the stated restrictions.

\section{Extinct cloning: neanderthal (Homo neanderthalensis)}

The idea of cloning Neanderthals has only come to public attention more recently (Church et al. 2013; Church and Regis 2012), and is seldom and incompletely discussed. Cloning Neanderthals carries with it not only the ethical aspects of cloning an extinct species, but is also constrained by one major difference: Neanderthals are closely related to humans (see Figure 3) and the biggest special consideration in evaluating the motivations and ethicality of cloning Neanderthals is whether they may merit human rights.

\section{Special considerations}

If it is unethical to clone humans, and if cloned Neanderthals would be morally equivalent to humans and receive human rights, then it is likewise unethical to clone Neanderthals. Cloning humans is widely considered to be unethical. Francis Collins, director of the Human Genome Project, argued:

Scientists, ethicists, theologians, and lawmakers are essentially unanimous that reproductive cloning of a human being should not be undertaken under any circumstances.... Implanting the product of human SCNT into a uterus is profoundly immoral and ought to be opposed on the strongest possible grounds. (Collins 2006)

Collins further explains that this opposition to human cloning extends to safety (Collins 2006). Ian Wilmut, leader of the project that resulted in Dolly the sheep, agrees 


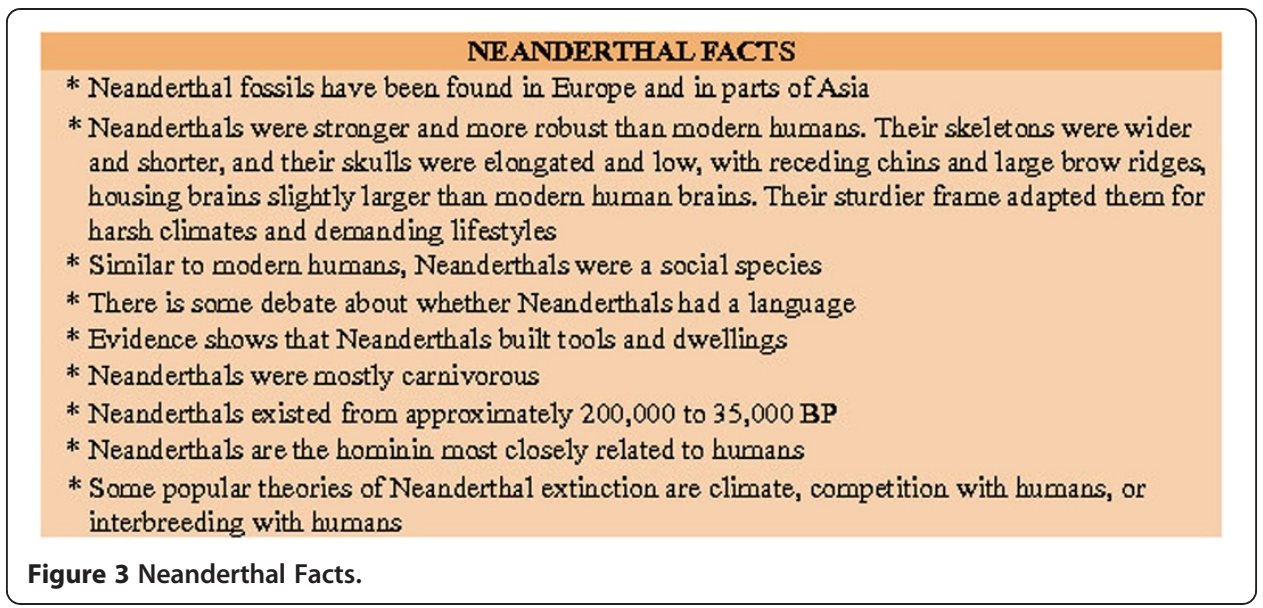

that cloning humans is 'criminally irresponsible' (Wilmut and Highfield 2006). Cloning humans is illegal in many states and countries and was banned by the U.N. in March of 2005 (Assembly 2005; Cameron and Henderson 2008). Laws vary on whether both reproductive and therapeutic human cloning are banned, but generally, cloning a human for reproductive purposes (to create a new human) is not an internationally sanctioned practice. Duties to these laws and bans make it unethical to clone humans. Further, by treating surrogate, donor, and clone as means, we violate most deontological considerations. Kant also described the importance of human dignity (Kant 2002), and German politician Brigitte Zypries argued against human cloning with the following idea:

It is...incompatible with human dignity-more specifically the dignity of the born human-to deny him what is part of every human existence: to stem from a random combination of the father's and the mother's hereditary construction. Regardless of whether we characterize this genetic combination as random, willed by God or as fate: its independence from human disposal is the basis from which human autonomy and thus human freedom accrue. (Zypries 2004)

Cloning humans is unethical because it reflects poorly on our humanity, violates our duties and the categorical imperative, and denies autonomy and human dignity.

While it appears unethical to clone humans, the question remains, does this include cloning Neanderthals? It seems so, if Neanderthals would have the moral status, rights, and privileges of humans. Neanderthals differed genetically from Homo sapiens, but today they might not be considered a separate species (Zorich 2010). Even if they are different, they would still likely receive the moral rights and privileges of humans. Law professor Lori Andrews said that 'there would be no question' that a cloned Neanderthal 'would be recognized as having human rights under the Constitution and international treaties' (Zorich 2010) Having these rights complicates matters, as Andrews described:

It's going to be studied and it's going to be experimented on. And yet, if it is accorded legal protections, it will have the right not to be the subject of research, so the very reasons for which you would create it would be an abridgment of rights. (Zorich 2010) 
Many of the motivations for cloning Neanderthals (for research, beasts of burden, etc.) are not permissible given that Neanderthals are legally equivalent to humans.

Neanderthals would receive human rights not only because of their legal equivalency to humans, but also for their behavioral and reproductive equivalency. Paleoanthropologist Trenton Holliday believes that if we raised 'a Neanderthal in a modern human family he would function just like everybody else...he could speak and do all the things that modern humans do' (Zorich 2010). (There is some debate about whether Neanderthals could speak, but they could certainly communicate somewhat; see (Barney 2012)). We would be hard-pressed not to give individuals human rights if they were behaviorally equivalent to humans. We would be ethically bound to treat Neanderthals as humans. Thus they could not be kept in labs or zoos, but ought to be incorporated into human society. As for reproductive potential, Neanderthals and humans may or may not have historically interbred (Zimmer 2013b; Eriksson and Manica 2012). If they were cloned, such interbreeding may happen, and the offspring of that union would most certainly receive human rights, so the potential reproductive equivalency of Neanderthals and humans suggests they would be considered humans, and the cloning of Neanderthals is equally unethical. All of this must be kept in mind in considering cloning this closely related species.

\section{Positive ethical aspects of cloning Neanderthals}

Similar to the mammoth, if humans contributed to the extinction of the Neanderthal, there is a vague but optional call for us to restore the species. George Church, a researcher who has recently (Boyle 2013) albeit perhaps mistakenly (Remal 2013) garnered attention as an avid advocate of cloning Neanderthals, wrote about this duty. He maintains that cloning a Neanderthal or any other animal minimizes the extinctions our Holocene epoch has wreaked on the world and increases species diversity (Church and Regis 2012). Increased species diversity is a nice idea, though not an ethically obligatory one. Even so our specific role in their extinction can never be fully known.

Other benefits of cloning Neanderthals with reasonable motivations have relevant and varied implications for humans. The technology for cloning Neanderthals will increase our knowledge about human development, which will aid efforts in therapeutic human cloning. Neanderthals may have genes that will help us develop resistance to human-specific diseases (Church and Regis 2012). These clones could also 'give Homo sapiens a sibling species that would allow us to see ourselves in new ways. It might give us an inkling into another form of human intelligence, or of different ways of thinking' (Church and Regis 2012). We may learn things about humans or Neanderthals, but the value of this knowledge is at best vague and undefined.

\section{Negative ethical aspects of cloning Neanderthals}

There seem to be few duties endorsing cloning Neanderthals. We cannot make 'cloning all extinct hominins' a universal maxim. We have a duty to obey laws, and therefore not to clone Neanderthals. Theoretically, if Neanderthals were denied human rights, they could be cloned to the benefit of humans. As beasts of burden, they could be used to make money for employers, or to improve clinical trials, drug development, and medical advancements with no loss of human life. However, these scenarios are blatantly unethical, for whether or not Neanderthals do receive human rights, this is 
using them as a means. Outside of these scenarios, we are still using them as a means and not as an ends; the overall purpose of cloning a Neanderthal is to study it and learn from it, which treats the end product of a cloned Neanderthal as a means-their end is a means, which is categorically unsound. Finally, it reflects poorly on humanity and dignity to clone Neanderthals, as described by two researchers, Jean-Jacques Hublin and James Noonan. Hublin said, 'We are not Frankenstein doctors who use human genes to create creatures just to see how they work' (Zorich 2010). James Noonan commented, 'If your experiment succeeds and [if] you generate a Neanderthal who talks, you have violated every ethical rule we have, and if your experiment fails...well. It's a lose-lose' (Zorich 2010). We cannot condone cloning Neanderthals for curiosity's sake alone because it deliberately violates ethical tenets.

Cloning Neanderthals also shares the disadvantages of cloning mammoths, but with different biological, economic, and societal costs. The surrogates in this case would likely be humans or other great apes (Church and Regis 2012), which is unacceptable, because it treats humans as a means and also subjects humans and endangered great apes to risks during egg retrieval or pregnancy and birth. The biological and environmental costs on the clones is also great, given that they have human rights; including weakened immune systems, inadequate metabolisms, and an inability to cope with current civilizations. They may also suffer socially, both for want of a social group and also as they fear or are the object of fear from society (Zorich 2010). Incorporating Neanderthals into human society somewhat alleviates our need to provide them with a social group, but this may also take a toll on our society. Some postulate that our society would also suffer in another way from cloning Neanderthals: 'What if the thing we learned from cloning a Neanderthal is that our curiosity is greater than our compassion? Would there be enough scientific benefit to make it worth the risks?' (Zorich 2010). Cloning Neanderthals would be bad for humans, for the clones, and for society at large.

\section{Conclusion on cloning Neanderthals}

The benefits of cloning Neanderthals are uncertain. The costs are heavy and certainly outweigh the benefits. Because it is unethical to clone humans and because Neanderthals would likely receive human rights, cloning Neanderthals would be considered unethical. While cloned Neanderthals offer possibilities for learning about hominin evolution and the medical advancements of humans, humans are not suffering due to lack of cloned Neanderthals. However, there remains concern that some might clone a Neanderthal regardless of its grave implications (Levy 2011). If Neanderthals were cloned, it seems unlikely to be justified and nothing more than our chance to say, 'We did it!' Surely the ethical implications of the effects on society and clones outweigh curiosity.

\section{Conclusion}

There is a worry that curious and unrestricted scientists will make these decisions about cloning before there is public debate about the issues. Scientists may worry that the biased and uninformed public will halt essential progress. Science is necessary to envisage such projects as these, and the public is necessary to make them possible. It is important in the case of cloning endangered and extinct species to adequately 
communicate about whether we should before focusing solely on whether we could. Francis Collins wisely wrote:

It would be a mistake to leave [these] decisions to the scientists. Scientists have a critical role to play in such debates, since they possess special expertise that may enable a clear distinction of what is possible and what is not. But scientists can't be the only ones at the table....Their moral sense is in general no more or less well developed than that of other groups, and they are unavoidably afflicted by a potential conflict of interest that may cause them to resent boundaries set by nonscientists. Therefore, a wide variety of other perspectives must be represented at the table. The burden is heavy upon those participating in such debates, however, to educate themselves about the scientific facts... [because] hardened positions can sometimes develop long before the nuances of the science have become clear, to the detriment of the potential for real dialogue. (Collins 2006)

Cloning cannot easily be simplified as 'ethical' or 'unethical', particularly in the case of endangered or extinct species. It is our hope that the discussion in this paper will open dialogue surrounding the current frontier in cloning. We should have discussion before beginning projects to curtail, restrict, or fund those projects we find the most ethical. When communication is complete, a moral future can be planned and enacted.

Abbreviations

SCNT: Somatic cell nuclear transfer; ENT: Embryonic nuclear transfer; DNA: Deoxyribonucleic acid.

Competing interests

The authors declare that they have no competing interests.

\section{Authors' contributions}

SC contributed to conception and design as well as drafted and completed the manuscript. JLJ edited and contributed to design of manuscript. SLP contributed to conception, design, and analysis of manuscript and gave final approval of the version to be published. All authors read and approved the final manuscript.

Authors' information

SC is completing graduate studies in the Department of Biology at Brigham Young University, JUJ is an Assistant Professor in the Department of Biology at Brigham Young University, and SLP is an Associate Professor in the Department of Biology at Brigham Young University.

\section{Acknowledgements}

We acknowledge the Brigham Young University Department of Biology for the support and facilitation for this work. We are especially grateful to Dr Byron Adams, Associate Professor at Brigham Young University for his revision and intellectual contributions to the article. We also thank Michael Cottrell and James McCarrey for their contributions to design and interpretation of the subject matter of the article.

Received: 20 June 2013 Accepted: 12 December 2013

Published: 10 Jan 2014

\section{References}

[CITES]. 2012. Convention on International Trade in Endangered Species of Wild Fauna and Flora. Appendices I, II and III. http://www.cites.org/eng/app/appendices.php. Accessed Apr 17, 2013.

Allentoft, ME. 2012. The half-life of DNA in bone: measuring decay kinetics in 158 dated fossils. Proceedings-Royal Society Biological sciences 279(1748): 4724-4733. Doi: 10.1098/rspb.2012.1745.

Assembly, General. 2005. Resolution adopted by the General Assembly 59/280. United Nations: United Nations Declaration on Human Cloning.

Barney, A. 2012. Articulatory capacity of Neanderthals, a very recent and human-like fossil hominin. Philosophical transactions-Royal Society Biological sciences 367(1585): 88-102. Doi: 10.1098/rstb.2011.0259.

Boyce, N. 2006. Pet-cloning business closes its doors. In All things considered. NPR News: NPR.

Boyle, A. 2013. Help wanted: 'Adventurous' woman to give birth to ... a Neanderthal baby? Jan 21.

De Cameron, NMS, and AV Henderson. 2008. Brave New World at the general assembly: the United Nations declaration on human cloning. Minnesota Journal of Law, Science \& Technology 9: 145-977.

Chadwick, RF. 1982. Cloning. Philosophy 57: 201-209. 
Church, G, B Philip, and G Johann. 2013. Interview with George Church: Can Neanderthals Be Brought Back from the Dead? In Spiegel online.

Church, GM, and E Regis. 2012. Regenesis: How Synthetic Biology Will Reinvent Nature and Ourselves. Washington: Basic Books.

Cibelli, JB, CH Keith, SE George, WD Michael, and LP Robert. 2002. The health profile of cloned animals. Nature Biotechnology 20: 13-14.

Collins, FS. 2006. The language of God: A scientist presents evidence for belief. New York: Free Press.

Culver, M, C Driscoll, E Eizirik, and G Spong. 2010. Genetic applications in wild felids. In Biology and conservation of wild felids, ed. DW Macdonald and AJ Loveridge, 107-123. New York: Oxford University Press.

Durant, SM, AJ Dickman, T Maddox, MN Waweru, T Caro, and N Pettorelli. 2010. Past, present, and future of cheetahs in Tanzania: their behavioural ecology and conservation. In The biology and conservation of wild felids, ed. DW Macdonald and AJ Loveridge, 373-382. New York: Oxford University Press.

Ehrenfeld, D. 2006. Transgenics and vertebrate cloning as tools for species conservation. Conservation Biology 20(3): 723-732. Doi: 10.1111/j.1523-1739.2006.00399.x.

Eriksson, A, and A Manica. 2012. Effect of ancient population structure on the degree of polymorphism shared between modern human populations and ancient hominins. Proceedings of the National Academy of Sciences of the United States 109: 13956-13960.

Fiester, A. 2005. Ethical issues in animal cloning. Perspectives in Biology and Medicine 48(3): 328-343. doi: 10.1353/ pbm.2005.0072.

Flock, E. 2012. South Korea clones American dog for \$50K after his death. http://www.washingtonpost.com/blogs/ blogpost/post/south-korea-clones-american-dog-for-50k-after-his-death/2012/01/17/glQAXi585P_blog.html. Accessed May 14, 2013.

Greely, H. 2013. De-extinction: Hubris or hope? In TEDxDeExtinction. Washington, DC, USA, TEDx: Grosvenor Auditorium.

Gross, L. 2013. De-Extinction Debate: Should Extinct Species Be Revived? In KQED Science. NPR. link: http://blogs.kqed. org/science/2013/06/05/deextinction-debate-should-extinct-species-be-revived/.

History, American Museum of Natural. 2009. Wild at heart: The plight of elephants in Thailand. In DVD Series Ecology, 1-2. New York, NY, USA: American Museum of Natural History Science Bulletins.

Jabr, F. 2013. Will cloning ever save endangered animals? www.scientificamerican.com/article.cfm?id=cloningendangered-animals. Accessed May 16, 2013.

Jadhav, S, and B Maan. 2012. The elephant vanishes: impact of human-elephant conflict on people's wellbeing. Health \& Place 18(6): 1356-1365. doi: http://dx.doi.org/10.1016/j.healthplace.2012.06.019.

Kant, I. 2002. Groundwork for the metaphysics of morals, Grundlegung zur Metaphysik der Sitten. Book, Whole: New Haven: Yale University Press.

Kant, I. 1790. Duties Towards Animals. In Bioethics: An anthology, ed. K Helga and S Peter, 564-565. Oxford: Blackwell Publishing.

Lane, R. 2006. Safety, identity and consent: a limited defense of reproductive human cloning. Bioethics 20(3): 125-135. Doi: 10.1111/j.1467-8519.2006.00486.x.

Lee, K. 2001. Can cloning save endangered species? Current Biology 11(7): R245-R246. doi: 10.1016/s0960-9822(01) 00126-9.

Levy, S. 2011. Once \& future giants: what Ice Age extinctions tell us about the fate of earth's largest animals. New York: Oxford University Press.

Lima, SL. 1998. Nonlethal effects in the ecology of predator-prey interactions. Bioscience 48(1): 25-34. Doi: 10.2307/ 1313225.

Lister, A, and P Bahn. 2007. Mammoths: Giants of the Ice Age. Berkeley, CA: Univeristy of California Press.

Loi, P, T Wakayama, J Saragustry, J Fulka Jr, and G Ptak. 2011. Biological time machines: a realistic approach for cloning an extinct mammal. Endangered Species Research 14(3): 227-233. Doi: 10.3354/esr00366.

Mueller, T. 2009. Ice Baby. National Geographic 215(5): 30-49.

News, BBC. 2004. Pet kitten cloned for Christmas. In BBC News.

Nicholls, H. 2008. Darwin 200: let's make a mammoth. Nature 456(7229): 310-314.

Nogués-bravo, D, R Jesús, H Joaquín, B Persaram, and MB Araújo. 2008. Climate change, humans, and the extinction of the woolly mammoth. PLoS biology 6(4): 686-692.

Panarace, M, Jl Aguero, M Garrote, G Jauregui, A Segovia, L Cane', J Gutierrez, M Marfil, F Rigali, M Pugliese, S Young, J Lagioia, C Garnil, JE Forte Pontes, JC Ereno Junio, S Mower, and M Medina. 2007. How healthy are clones and their progeny: 5 years of field experience. Theriogenology 67: 142-151.

Pina-Aguilar, RE, J Lopez-Saucedo, R Sheffield, LI Ruiz-Galaz, JJ De Barroso-Padilla, and A Gutierrez-Gutierrez. 2009. Revival of extinct species using nuclear transfer: hope for the mammoth, true for the pyrenean ibex, but is it time for "Conservation Cloning"? Cloning and Stem Cells 11(3): 341-346. Doi: 10.1089/clo.2009.0026.

Plume, K. 2009. Welcome to the clone farm. In Reuters. Thomson Reuters. http://www.reuters.com/article/2009/11/13/ us-food-cloning-idUSTRE5AC07V20091113.

Poland, SC, and $\sqcup$ Bishop. 2002. Bioethics and cloning, part I. Kennedy Institute of Ethics Journal 12(3): 305-324. Doi: 10.1353/ken.2002.0014.

Rees, PA. 2001. Is there a legal obligation to reintroduce animal species into their former habitats? Oryx 35(3): 216-223. Doi: 10.1046/j.1365-3008.2001.00178.x

Remal, GJ. 2013. Harvard professor blasts Neanderthal clone baby rumor on web. Boston Herald. January 22. link: http:// bostonherald.com/news_opinion/local_coverage/2013/01/harvard_professor_blasts_neanderthal_clone_baby_ rumor_web.

RT. 2013. Mammoth find: Preserved Ice Age giant found with flowing blood in Siberia. In RT News. RT. link: http://rt. com/news/mammoth-blood-ice-siberia-908/.

Ryder, OA. 2002. Cloning advances and challenges for conservation. Trends in Biotechnology 20(6): 231-232. doi: 10.1016/s0167-7799(02)01954-6. 
Ryder, OA, and K Benirschke. 1997. The potential use of "cloning" in the conservation effort. Zoo Biology 16(4): 295-300. doi: 10.1002/(sici)1098-2361(1997)16:4<295::aid-zoo1>3.0.co;2-5.

Shiels, M. 2004. Carbon kitty's $\$ 50,000$ price tag. BBC News. http://news.bbc.co.uk/2/hi/science/nature/3663277.stm. Accessed May 14, 2013.

Stone, R. 1999. Cloning the woolly mammoth: (Cover story). Discover 20(4): 56

Stone, R. 2002. Mammoth: The resurrection of an ice age giant. Cambridge: Perseus Publishing.

TEDx. 2013. TEDxDeExtinction. Washington DC, United States: Grosvenor Auditorium. Partnership with National Geographic Society.

Thomas, MG. 2012. The flickering genes of the last mammoths. Molecular Ecology 21(14): 3379-3381. Doi: 10.1111/ j.1365-294X.2012.05594.X

Van Den Belt, H. 2009. Playing God in Frankenstein's footsteps: synthetic biology and the meaning of life. Nanoethics 3(3): 257-268.

Wells, DN. 2005. Animal cloning: problems and prospects. Revue Scientifique Et Technique-Office International Des Epizooties 24(1): 251-264.

Wilmut, I, AE Schnieke, J Schnieke, A Mcwhir, J Kind, and KHS Campbell. 1997. Viable offspring derived from fetal and adult mammalian cells. Nature 385(6619): 810-813.

Wilmut, I, and R Highfield. 2006. After Dolly: The uses and misuses of human cloning. New York: W. W. Norton \& Company.

Woodford, J, and Sydney morning Herald. 2000. Get a life, scientists tell extinct tiger. May 5.

Zimmer, C. 2013a. Bringing them back to life. National Geographic Magazine 223(4): 28.

Zimmer, C. 2013b. Interbreeding with Neanderthals. Discover 34(2): 38-44.

Zorich, Z. 2010. Should we clone neanderthals? The scientific, legal, and ethical obstacles. Archaeology 63(2): 34-41.

Zypries, B. 2004. From procreation to generation? Constitutional and legal-political issues in bioethics. In Human dignity and human cloning, ed. S Vöneky and R Wolfrum, 107-121. Leiden: Martinus Nijhoff Publishers.

10.1186/2195-7819-10-3

Cite this article as: Cottrell et al:: Resuscitation and resurrection: The ethics of cloning cheetahs, mammoths, and Neanderthals. Life Sciences, Society and Policy 2014, 10:3

Submit your manuscript to a SpringerOpen ${ }^{\circ}$ journal and benefit from:

- Convenient online submission

Rigorous peer review

- Immediate publication on acceptance

- Open access: articles freely available online

- High visibility within the field

- Retaining the copyright to your article

Submit your next manuscript at $\gg$ springeropen.com 